\title{
Factors predicting reoperation of chronic subdural hematoma following primary surgical evacuation
}

\author{
Rouzbeh Motiei-Langroudi, MD, Martina Stippler, MD, Siyu Shi, BS, Nimer Adeeb, MD, \\ Raghav Gupta, BS, Christoph J. Griessenauer, MD, Efstathios Papavassiliou, MD, \\ Ekkehard M. Kasper, MD, PhD, Jeffrey Arle, MD, PhD, Ron L. Alterman, MD, \\ Christopher S. Ogilvy, MD, and Ajith J. Thomas, MD
}

Neurosurgical Service, Beth Israel Deaconess Medical Center, Harvard Medical School, Boston, Massachusetts

OBJECTIVE Chronic subdural hematoma (CSDH) is commonly encountered in neurosurgical practice. However, surgical evacuation remains complicated by a high rate of reoperation. The optimal surgical approach to reduce the reoperation rate has not been determined. In the current study, the authors evaluated the prognostic value of clinical and radiographic factors to predict reoperation in the context of CSDH.

METHODS A retrospective review of $325 \mathrm{CSDH}$ patients admitted to an academic medical center in the United States, between 2006 and 2016, was performed. Clinical and radiographic factors predictive of the need for CSDH reoperation were identified on univariable and multivariable analyses.

RESULTS Univariable analysis showed that warfarin use, clopidogrel use, mixed hypo- and isointensity on T1-weighted $\mathrm{MRI}$, greater preoperative midline shift, larger hematoma/fluid residual on first postoperative day CT, lesser decrease in hematoma size after surgery, use of monitored anesthesia care (MAC), and lack of intraoperative irrigation correlated with a significantly higher rate of reoperation. Multivariable analysis, however, showed that only the presence of loculation, clopidogrel or warfarin use, and percent of hematoma change after surgery significantly predicted the need for reoperation. Our results showed that $0 \%$ (no reduction), $50 \%$, and $100 \%$ hematoma maximum thickness change (complete resolution of hematoma after surgery) were associated with a $41 \%, 6 \%$, and $<1 \%$ rate of reoperation, respectively. The use of drains, either large diameter or small caliber, did not have any effect on the likelihood of reoperation.

CONCLUSIONS Among many factors, clopidogrel or warfarin use, hematoma loculation on preoperative $\mathrm{CT}$, and the amount of hematoma evacuation on the first postoperative CT were the strongest predictors of reoperation.

https://thejns.org/doi/abs/10.3171/2017.6.JNS17130

KEY WORDS chronic subdural hematoma; recurrence; evacuation; reoperation; vascular disorders

$\mathrm{C}$ HRONIC subdural hematoma (CSDH) is a common form of intracranial hemorrhage, but its optimal management remains unclear. Following surgical evacuation, CSDH may recur at a rate of $2.3 \%$ to $38.7 \%$ depending on the operative techniques employed. ${ }^{6,7,10,20,21}$

Several studies have been undertaken in an effort to identify predictors for CSDH recurrence. However, the factors predicting recurrence are not clear yet. In many of these studies, coagulopathy or anticoagulant drug use, 3,7 , 13,20,25 male sex, ${ }^{10,25}$ hypertension, ${ }^{20,22}$ diabetes, ${ }^{3,17,22}$ bilateral hematomas, ${ }^{20,22}$ larger preoperative hematoma volume, ${ }^{3,23}$ septations, ${ }^{6,23,24}$ heterogeneous or mixed density on CT, ${ }^{8,11,18,22,23}$ iso- or hypointensity on T1-weighted MRI, ${ }^{4}$ preoperative midline shift, ${ }^{20,24}$ persistence of mass effect after surgery, ${ }^{3,13}$ larger postoperative residual hematoma, ${ }^{6,23}$ and postoperative pneumocephalus ${ }^{9,16,24}$ were found to be associated with an increased rate of recurrence. The risk of recurrence is reduced with hematomas that appeared homogenous on preoperative imaging. ${ }^{3,24}$ More controversial are other factors including the type of surgery, ${ }^{15}$ use of a subdural drain, ${ }^{12,19,21,27}$ intraoperative irrigation, ${ }^{7,9,25}$ and postoperative posture. ${ }^{1}$

Most of these studies have evaluated recurrence risk with only a single or few predictors, possibly missing the

ABBREVIATIONS BHD = burr hole drainage; $\mathrm{CSDH}=$ chronic SDH; EVD = external ventricular drain; $\mathrm{GCS}=$ Glasgow Coma Scale; MAC = monitored anesthesia care; $\mathrm{SDH}=$ subdural hematoma.

SUBMITTED January 13, 2017. ACCEPTED June 5, 2017.

INCLUDE WHEN CITING Published online December 15, 2017; DOI: 10.3171/2017.6.JNS17130. 
interaction of other variables and confounders. In the current study, we intended to address this problem using a database maintained by a group of neurosurgeons at a single large academic institution for over 10 years. We focused on identifying risk factors associated with the need for repeat surgery for the treatment of CSDH.

\section{Methods}

\section{Inclusion of Patients}

We retrospectively reviewed consecutive cases involving patients who presented with CSDH to an academic tertiary care center in the United States between 2006 and 2016 and were treated with surgical evacuation.

\section{Included Variables}

The following data were recorded: sex, age, operation date, history of trauma or other mechanism, comorbidities, anticoagulant use and type (including aspirin, warfarin, clopidogrel, ticagrelor, heparin, etc.), presenting Glasgow Coma Scale (GCS) score, preoperative neurological deficits, hematoma characteristics (laterality, density characteristics on $\mathrm{CT}$, intensity on MRI, maximum thickness, location, and presence or absence of membranes and loculations), preoperative midline shift, postoperative CT characteristics (pneumocephalus, maximum hematoma/ fluid thickness after surgery, and percent hematoma thickness change after surgery), intraoperative details (type of anesthesia, type of surgery, number and location of burr holes [in cases of burr hole evacuation], opening of any existing internal membrane, saline irrigation volume, use of drain, drain type [external ventricular drain (EVD), Jackson-Pratt, or Blake-Bard], including the respective drain size), complications, and whether the patient required additional surgery to evacuate a recurrent hematoma. Percent hematoma change after surgery was calculated using the same axial CT cut and the following equation: (preoperative maximum hematoma thickness - postoperative maximum hematoma thickness)/preoperative maximum hematoma thickness.

The most recent follow-up data, including status of the CSDH (confirmed by an imaging modality), were also recorded.

The outcome measure was reoperation after the first surgery (due to residual hematoma, continued symptoms, acute SDH, or recurrence within 3 months). Although there was no unified institutional protocol, the decision to operate was generally made based on either worsening of neurological symptoms or continued or increased midline shift on the postoperative CT. Univariable (independent t-test), bivariable (chi-square), and multivariable (multiple logistic regression) analyses were performed to determine which, if any, of the studied factors were associated with an increased risk of reoperation. The multivariable logistic regression was performed only with variables that yielded a $\mathrm{p}$ value $<0.1$ in univariable analysis. Moreover, probit analysis was used to make probability predictions based on percent hematoma evacuation and preoperative midline shift. Statistical analysis was performed using PASW Statistics 18 (Predictive Analytics Software, SPSS Inc.). Statistical significance was defined by a $\mathrm{p}$ value $<0.05$.
TABLE 1. Frequency of repeat operations in 325 patients with CSDH

\begin{tabular}{cl}
\hline No. of Repeat Ops & \multicolumn{1}{c}{ No. of Patients $^{*}$} \\
\hline 0 & 224 w/ unilat SDH, 57 w/ bilat \\
\hline 1 & 32 w/ unilat SDH, 2 w/ bilat \\
\hline 2 & 6 (all w/ unilat SDH) \\
\hline 3 & 2 (all w/ unilat SDH) \\
\hline 4 & 2 (all w/ unilat SDH) \\
\hline
\end{tabular}

* Four patients died during their initial hospitalization. These patients are included in the count of patients with no repeat operations.

\section{Results}

\section{Patient and Treatment Demographics}

During the study period, 325 patients (mean age 71.6 years, range 28-98 years, male/female ratio 2.3) underwent a total of 446 operations. Unilateral evacuations were performed in 266 patients and bilateral evacuations in 59. A CT scan was always performed within the first 24 hours after surgery. The mean postoperative follow-up period for the entire patient cohort was 20.2 months (range 1-119 months). There were 191 burr hole drainages (BHDs) and 255 craniotomies. The number of patients with and without reoperations is shown in Table 1. A $12.9 \%$ reoperation rate was observed. Complications are summarized in Table 2 . All cases complicated by clinically significant acute SDH required repeat surgery $(\mathrm{p}<0.05)$, but other complications did not influence reoperation. There were 4 deaths.

\section{Antiplatelet and Anticoagulant Therapies}

Prior to surgery, 81, 70, 24, and 3 patients were receiving, respectively, aspirin, warfarin, clopidogrel, and ticagrelor. Six patients (previously on warfarin) were receiving heparin before their second surgery. Twenty-four patients were receiving more than one of these drugs. All patients on anticoagulant/antiplatelet therapy received reversal treatment before undergoing surgery (intravenous vitamin K plus either fresh frozen plasma or prothrombin complex concentrate for warfarin, platelet infusion for clopidogrel and aspirin, and protamine for heparin). The mean international normalized ratio (INR) on the day of surgery was 1.2 (range 1.0-1.6). The preoperative hematoma thickness and percent hematoma thickness change were not different in patients receiving anticoagulant/an-

TABLE 2. Complications observed in the perioperative period

\begin{tabular}{lc}
\hline \multicolumn{1}{c}{ Complication } & No. of Pts \\
\hline Acute SDH & 7 \\
\hline $\mathrm{ICH}$ & 2 \\
\hline Acute coronary syndrome & 2 \\
\hline Arterial thrombosis (at site of arterial line insertion) & 1 \\
\hline Seizures & 1 \\
\hline Subdural empyema & 1 \\
\hline Encephalopathy & 1 \\
\hline
\end{tabular}

$\mathrm{ICH}=$ intracerebral hemorrhage; pts = patients. 
tiplatelet therapy compared with those who did not ( $\mathrm{p}=$ 0.67 and $p=0.79$, respectively).

\section{Univariate and Bivariate Analyses of Factors Predicting Reoperation}

We first evaluated the association of various individual clinical variables with the need for reoperation. Univariable analysis showed that use of warfarin or clopidogrel, mixed hypo- and isointensity on T1-weighted MRI, greater preoperative midline shift, greater hematoma/fluid thickness on 1st postoperative day CT, less decrease in maximum hematoma thickness after surgery, use of monitored anesthesia care (MAC), and lack of intraoperative irrigation all led to significantly higher rates of reoperation. Factors such as sex, age, use of aspirin, heparin, or ticagrelor, presenting GCS score, presence of neurological deficits, hematoma side, preoperative hematoma thickness, preoperative hematoma density characteristic in CT, hematoma location, presence of air on postoperative CT, opening the internal membrane during surgery, surgical evacuation technique (BHD or craniotomy), and number and location of burr holes, however, did not affect the reoperation rate. The presence of loculations on preoperative CT, a larger amount of intraoperative irrigation volume, lack of drain use or use of smaller size drains (EVD) showed a nonsignificant trend toward higher reoperation rate (Fig. 1 and Table 3).

\section{Multivariate Analysis of Factors Predicting Reoperation}

Multivariate analysis showed that presence of loculations, clopidogrel use, warfarin use, increased amount of residual hematoma/fluid, and decreased percent hematoma change after surgery significantly predicted the need for reoperation (Table 3).

\section{Analysis of Probability of Reoperation}

We performed a probit analysis to show the probability of reoperation based on the percent change in hematoma thickness and the preoperative midline shift. Results showed that $0 \%$ (no reduction), $50 \%$, and $100 \%$ (complete resolution of hematoma after surgery) changes in hematoma thickness were associated with $41 \%, 6 \%$, and $<1 \%$ reoperation rates, respectively $(\mathrm{p}<0.001)$. To evaluate if the same trend existed in spite of different preoperative hematoma thickness values, we then stratified the data based on preoperative hematoma thickness $(0-$ to $1-\mathrm{cm}, 1-$ to 2-cm, 2- to 3-cm, and 3- to 4-cm groups) and repeated the probit analysis for the probability of reoperation based on the percent change in hematoma thickness (Fig. 2). Multivariable analysis showed that both percent change in hematoma thickness and stratified preoperative hematoma thickness values significantly predicted the need for reoperation ( $\mathrm{p}=0.001$ and 0.004 , respectively). In addition, $0-\mathrm{mm}, 8.6-\mathrm{mm}, 14.5-\mathrm{mm}, 19.6-\mathrm{mm}$, and $24.1-\mathrm{mm}$ shifts were associated with $9 \%, 15 \%, 20 \%, 25 \%$, and $30 \%$ probability rates of reoperation, respectively $(\mathrm{p}=0.018)$.

\section{Discussion}

CSDH is a common form of intracranial hemorrhage. If large or symptomatic, it is addressed surgically through burr hole trephination or craniotomy, with a reported recurrence rate ranging from $2.3 \%$ to $38.7 \%$ for different surgical techniques. ${ }^{6,7,10,20,21}$ Although many investigators have tried to elucidate factors responsible for recurrence and reoperation, there is an ongoing debate about which parameters are relevant in this matter. Among the established factors are presence of coagulopathy or anticoagulant drug use, presence of CSDH loculations, larger preoperative hematoma volume, presence of significant postoperative residual hematoma, and postoperative pneumocephalus. $3,6,7,10,13,16,20,23-25$ In 2 meta-analyses that included 19 randomized clinical trials and 250 studies each, heterogeneity of hematoma on $\mathrm{CT}$, use of intraoperative irrigation, and drain use were identified as factors predictive of the need for reoperation.,14 Table 4 summarizes studies that investigated factors predicting an increased or decreased risk of recurrence or need for reoperation. Several studies, however, have evaluated recurrence risk

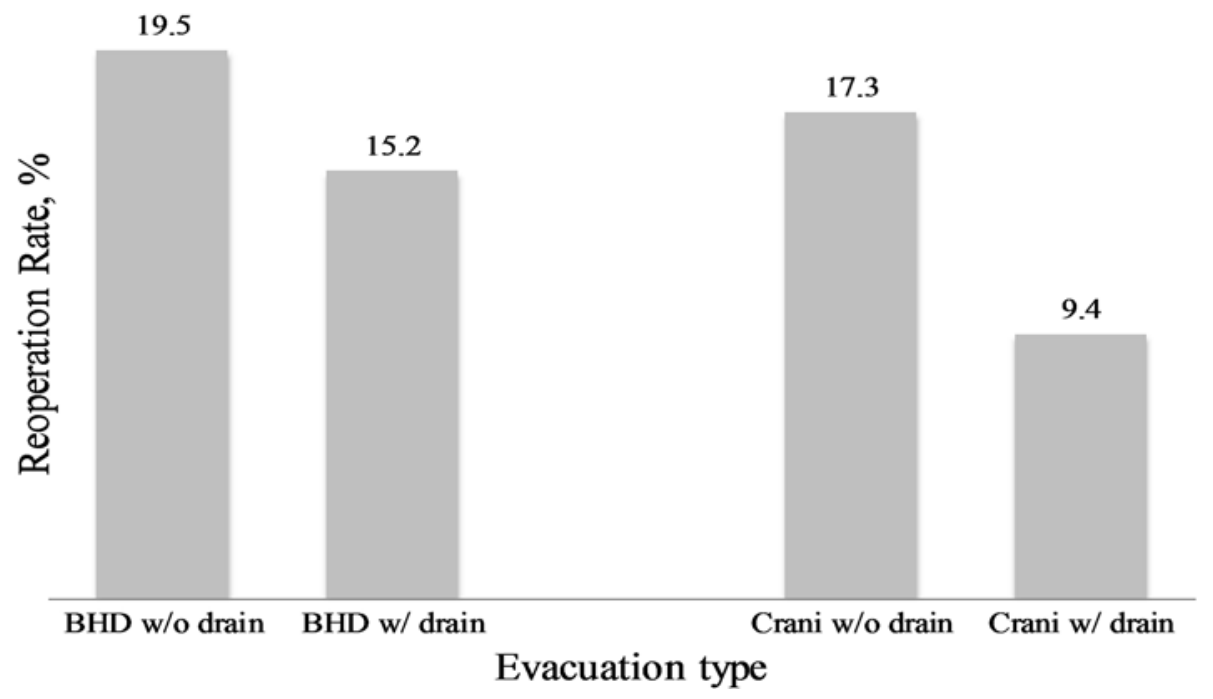

FIG. 1. Reoperation rate based on surgical approach and drain use. Crani = craniotomy. 
TABLE 3. Effects of variables on reoperation

\begin{tabular}{|c|c|c|c|c|c|}
\hline Variable & Reop Pts & Non-Reop Pts & $\begin{array}{l}\text { p Value, Uni- } \\
\text { \& Bivariable } \\
\text { Analysis }\end{array}$ & $\begin{array}{c}\text { p Value, } \\
\text { Multivariable } \\
\text { Analysis }\end{array}$ & $\begin{array}{c}\text { OR }(95 \% \mathrm{Cl}) \\
\text { Multivariable Analysis }\end{array}$ \\
\hline \multicolumn{6}{|l|}{ Demographic \& clinical characteristics } \\
\hline Sex & & & 0.08 & 0.9 & NA \\
\hline Male & $84.1 \%$ & $66.3 \%$ & & & \\
\hline Female & $15.9 \%$ & $33.7 \%$ & & & \\
\hline Anticoagulant use & $60.6 \%$ & $51.1 \%$ & 0.19 & & \\
\hline Aspirin & $24.2 \%$ & $27.0 \%$ & 0.32 & NA & NA \\
\hline Clopidogrel & $18.2 \%$ & $5.2 \%$ & $0.006^{* *}$ & 0.04 & $9.9(1.1-90.9)$ \\
\hline Warfarin & $36.4 \%$ & $21.3 \%$ & $0.04^{*}$ & 0.03 & $7.9(1.2-50)$ \\
\hline Heparin & $3.0 \%$ & $1.7 \%$ & 0.29 & NA & NA \\
\hline Ticagrelor & $0 \%$ & $1.1 \%$ & 0.27 & NA & NA \\
\hline Neurological deficit & $48.7 \%$ & $50.5 \%$ & 0.14 & NA & NA \\
\hline \multicolumn{6}{|l|}{ Imaging characteristics } \\
\hline Hematoma side & NA & NA & 0.93 & NA & NA \\
\hline Hematoma density in CT & & & 0.91 & NA & NA \\
\hline Mixed (hyper- \& hypodense) & $57.9 \%$ & $51.3 \%$ & & & \\
\hline Hypodense & $21.1 \%$ & $22.3 \%$ & & & \\
\hline Isodense & $21.1 \%$ & $23.7 \%$ & & & \\
\hline Hematoma intensity in T1 MRI & & & $0.004^{* *}$ & 0.99 & NA \\
\hline Hypointense & $0 \%$ & $19.6 \%$ & & & \\
\hline Mixed hypo- \& isointense & $40 \%$ & $0 \%$ & & & \\
\hline Isointense & $0 \%$ & $34.8 \%$ & & & \\
\hline Mixed hyper- \& isointense & $0 \%$ & $0 \%$ & & & \\
\hline Hyperintense & $60 \%$ & $43.5 \%$ & & & \\
\hline Hematoma intensity in T2 MRI & & & 0.15 & NA & NA \\
\hline Hypointense & $0 \%$ & $0 \%$ & & & \\
\hline Mixed hypo- \& isointense & $0 \%$ & $0 \%$ & & & \\
\hline Isointense & $20 \%$ & $19.6 \%$ & & & \\
\hline Mixed hyper- \& isointense & $40 \%$ & $4.3 \%$ & & & \\
\hline Hyperintense & $40 \%$ & $76.1 \%$ & & & \\
\hline Hematoma location & & & 0.10 & 0.74 & NA \\
\hline Hematoma loculation & $51.9 \%$ & $46.2 \%$ & 0.08 & $0.003^{* *}$ & $12.3(2.7-54.3)$ \\
\hline Postop air & $94.7 \%$ & $91.8 \%$ & 0.70 & NA & NA \\
\hline \multicolumn{6}{|l|}{ Op characteristics } \\
\hline Internal membrane opening & $69.0 \%$ & $56.8 \%$ & 0.11 & 0.78 & NA \\
\hline Anesthesia method & & & $<0.001^{* * *}$ & 0.37 & NA \\
\hline Intubation & $96.4 \%$ & $99.7 \%$ & & & \\
\hline MAC & $3.6 \%$ & $0.3 \%$ & & & \\
\hline Evacuation technique & & & 0.84 & NA & NA \\
\hline Craniotomy & $55.2 \%$ & $58.2 \%$ & & & \\
\hline Burr hole & $44.8 \%$ & $41.8 \%$ & & & \\
\hline Burr hole location (for BHD only) & & & 0.50 & NA & NA \\
\hline Frontal & $23.1 \%$ & $14.6 \%$ & & & \\
\hline Frontal \& parietal & $61.5 \%$ & $60.9 \%$ & & & \\
\hline Parietal & $15.4 \%$ & $24.5 \%$ & & & \\
\hline No. of burr holes, mean & 1.6 & 1.6 & 0.75 & NA & NA \\
\hline Irrigation & $93.1 \%$ & $98.4 \%$ & $0.02^{*}$ & 0.67 & NA \\
\hline Drain use & $39.7 \%$ & $49.1 \%$ & 0.32 & NA & NA \\
\hline Drain type & & & 0.49 & NA & NA \\
\hline None & $51.6 \%$ & $61.4 \%$ & & & \\
\hline Small (EVD) & $15.8 \%$ & $15.8 \%$ & & & \\
\hline Large (Jackson-Pratt, Blake-Bard) & $32.6 \%$ & $22.8 \%$ & & & \\
\hline
\end{tabular}




\begin{tabular}{|c|c|c|c|c|c|}
\hline Variable & Reop Pts & Non-Reop Pts & $\begin{array}{c}\text { p Value, Uni- } \\
\text { \& Bivariable } \\
\text { Analysis }\end{array}$ & $\begin{array}{c}\text { p Value, } \\
\text { Multivariable } \\
\text { Analysis }\end{array}$ & $\begin{array}{c}\text { OR }(95 \% \mathrm{Cl}) \\
\text { Multivariable Analysis }\end{array}$ \\
\hline \multicolumn{6}{|l|}{ Univariable analysis } \\
\hline Age in yrs, mean & 74.0 & 71.2 & 0.16 & NA & NA \\
\hline Presenting GCS score, mean & 14.1 & 14.5 & 0.30 & NA & NA \\
\hline Hematoma thickness before op $(\mathrm{mm})$, mean & 20.9 & 19.1 & 0.06 & 0.16 & $1.1(0.98-1.2)$ \\
\hline Hematoma thickness on 1st postop day (mm), mean & 15.5 & 11.3 & $<0.001^{* * *}$ & $<0.001^{* * *}$ & \\
\hline Percent hematoma thickness change after op, mean & 23.3 & 41.6 & $<0.001^{* * *}$ & $<0.001^{* * *}$ & $0.95(0.93-0.97)$ \\
\hline Midline shift before op (mm), mean & 7.9 & 6.1 & $0.01^{*}$ & 0.44 & $1.1(0.9-1.3)$ \\
\hline Irrigation vol (liters), mean & 2.3 & 1.5 & 0.06 & 0.09 & $5.1(0.8-32.4)$ \\
\hline Drain external size $(\mathrm{mm})$, mean & 2.3 & 2.9 & 0.21 & NA & NA \\
\hline
\end{tabular}

$\mathrm{NA}=$ not applicable.

* $p<0.05$.

** $p<0.01$.

$* * * \quad p<0.001$

60

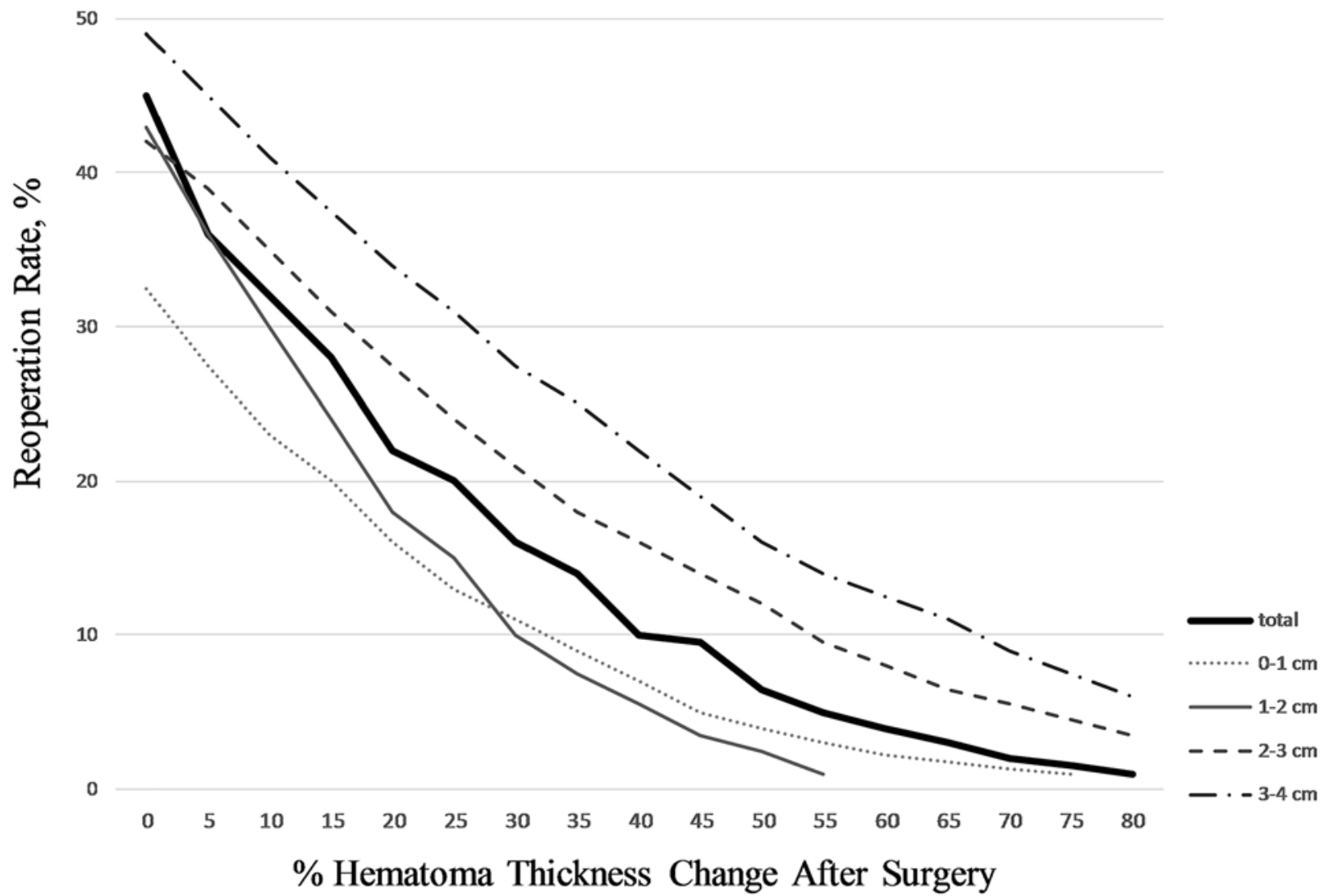

FIG. 2. Probability of need for reoperation based on percent hematoma thickness change after surgery. The data for the whole series of patients and data after stratification based on preoperative hematoma thickness are shown. 
TABLE 4. Published studies with predictors of CSDH recurrence

\begin{tabular}{|c|c|c|c|}
\hline \multirow[b]{2}{*}{ Authors \& Year } & \multirow{2}{*}{$\begin{array}{l}\text { No. of } \\
\text { Pts }\end{array}$} & \multicolumn{2}{|l|}{ Outcome } \\
\hline & & Higher Recurrence & Lower Recurrence \\
\hline Ro et al., 2016 & 130 & & $\begin{array}{l}\text { Younger age ( }<75 \text { yrs), isodensity } \\
\text { of hematoma on CT, \& short } \\
\text { duration from symptom to op }\end{array}$ \\
\hline Jang et al., 2015 & 93 & & $\begin{array}{l}\text { Double burr hole, irrigation, \& lack } \\
\text { of coagulopathy }\end{array}$ \\
\hline Kim et al., 2015 & 368 & $\begin{array}{l}\text { Male pts, pts w/ malignant neoplasm history, single-layer CSDH \& isoden- } \\
\text { sity CSDH }\end{array}$ & \\
\hline Schwarz et al., 2015 & 193 & $\begin{array}{l}\text { Midline shift, arterial hypertension, bilat hematomas, \& prior treatment w/ vit } \\
\mathrm{K} \text { antagonists }\end{array}$ & \\
\hline Leroy et al., 2015 & 140 & Preop anticoagulant therapy \& mass effect on postop CT scan & \\
\hline Goto et al., 2015 & 429 & MRI T1 iso-/hypointensity & \\
\hline Pang et al., 2015 & 303 & Hematological disease, prior shunt op, \& DM & \\
\hline Jack et al., 2015 & 331 & CSDH septation \& larger postop SDH vol & \\
\hline Kim et al., 2014 & 152 & Irrigation, postop pneumocephalus & \\
\hline Song et al., 2014 & 97 & $\begin{array}{l}\text { Heterogeneous density in } \mathrm{CT} \text {, hypertension, DM, early removal of drainage } \\
\text { tube, bilat hematomas }\end{array}$ & \\
\hline Singh et al., 2014 & 246 & & Use of drain \\
\hline Jeong et al., 2014 & 125 & High- or mixed-density in CT & \\
\hline Stanišić et al., 2013 & 107 & $\begin{array}{l}\text { The preop hematoma vol, iso- or hyperdensity in CT, laminar \& separated } \\
\text { CT densities, higher residual total hematoma cavity vol on 1st postop day }\end{array}$ & \\
\hline Ohba et al., 2013 & 177 & Large pneumocephalus & \\
\hline Chon et al., 2012 & 420 & $\begin{array}{l}\text { Postop midline shift } \geq 5 \mathrm{~mm} \text {, DM, preop } \mathrm{Sz} \text {, preop hematoma thickness } \geq 20 \\
\mathrm{~mm} \text {, anticoagulant therapy, laminar \& separated CT density }\end{array}$ & Homogeneous CT density \\
\hline Tahsim-Oglou et al., 2012 & 247 & Male sex \& use of enoxaparin & Copious intraop irrigation \\
\hline Santarius et al., 2009 & 269 & & Drain insertion \\
\hline Mondorf et al., 2009 & 193 & Craniotomy & Burr-hole evacuation \\
\hline Yu et al., 2009 & 97 & & Duration of drainage $>3$ days \\
\hline Ko et al., 2008 & 255 & High or mixed density in CT & \\
\hline Abouzari et al., 2007 & 84 & Assuming an upright posture soon after op & \\
\hline Stanišić et al., 2005 & 99 & $\begin{array}{l}\text { Separated type, frontal base type, a midline shift }>5 \mathrm{~mm} \text {, presence of acute } \\
\text { subdural clots, interval from head trauma to initial surgery }<60 \text { days, } \\
\text { hematoma thickness }>10 \mathrm{~mm} \text {, \& massive pneumocephalus }\end{array}$ & Homogeneous CT density \\
\hline
\end{tabular}

$\mathrm{DM}=$ diabetes mellitus; $\mathrm{Sz}=$ seizure; vit = vitamin.

with respect to a few factors, likely missing the interaction between other variables and confounders. Our study is among the largest series reported to date.

Our results confirm previous observations showing that the volume of residual hematoma/fluid, degree of midline shift, and presence of loculations on the preoperative scans predict the need for repeat surgery. In fact, our results showed that the volume of residual hematoma/fluid (calculated either alone or in relation to the preoperative volume as "percent hematoma change") is the strongest factor predicting a need for repeat surgery in CSDH. Our analysis model showed that a 50\% decrease in maximum hematoma thickness on the first postoperative CT is associated with a less than $10 \%$ risk of reoperation. We also observed that the absence of change in hematoma volume resulted in a $41 \%$ reoperation rate (not $100 \%$ as would be expected). One explanation for this observation would be that the fluid collected after surgery is a mixture of resid- ual hematoma fluid, CSF, and irrigation fluid. Therefore, there is not always a need to go back to immediate reoperation as this residual collection is different from the initial scan and will resolve over time in a substantial number of patients. Indeed, with expectant therapy in neurologically stable patients, good outcomes would likely be observed. Stratification of data based on preoperative hematoma thickness $(0-1 \mathrm{~cm}, 1-2 \mathrm{~cm}, 2-3 \mathrm{~cm}$, and $3-4 \mathrm{~cm})$ showed a similar trend.

Our study built on the current body of literature by addressing newer and less-investigated predictive factors. Although anticoagulant and antiplatelet use is well known as a risk factor for recurrence, $, 3,7,13,20,25$ this is the first study to investigate various agents individually and more specifically. We found that only warfarin and clopidogrel (and not aspirin) are associated with a higher risk of reoperation. Among imaging characteristics of the hematoma, the most significant prognostic factors for reoperation, other 
than midline shift, hematoma volume (or thickness), and loculation, are its MRI characteristics. Our results showed a significantly higher reoperation rate in hematomas showing mixed iso- and hypointensities on T1-weighted MRI. The predictive role of MRI has been previously shown in very few studies. Goto et al., for instance, found that T1-weighted MRI is the single strongest imaging modality predicting recurrence in CSDH. ${ }^{4}$ However, MRI is not routinely performed in $\mathrm{CSDH}$, decreasing its relevance in everyday practice. We also showed that the mode of anesthesia plays a role in determining the rate of repeat surgery, as there were more reoperations in patients who were not placed under general anesthesia for the initial operation (i.e., those in whom MAC or intravenous sedation was used). Regarding the role of intraoperative saline irrigation, we showed that the outcome is better in cases in which irrigation was employed, which is in agreement with results published by other groups. ${ }^{5,7,25}$ We also showed that the results seem best with $1-1.5 \mathrm{~L}$ of irrigation, but not with copious amounts exceeding $2 \mathrm{~L}$.

Our results did not confirm and validate a role for opening the internal hematoma membrane in accordance with previous findings by others. ${ }^{26}$ Although prior studies have shown that use of a subdural drain reduces the recurrence rate in $\mathrm{CSDH},{ }^{14,21}$ our data were more controversial in this regard. We showed a decrease, albeit a statistically nonsignificant one, in the reoperation rate for patients who had a drain placed (both for those who underwent BHD and those who underwent craniotomy). We also showed the same trend regarding drain size (i.e., lower reoperation using larger drains).

Our results suggest that neither evacuation type (BHD vs craniotomy) nor opening of internal membranes (which can be better achieved through craniotomy) had a statistically significant influence on reoperation, in accordance with the results of a previous decision analysis that showed a higher utility of BHD compared with craniotomy, as craniotomy was associated with fewer recurrences but more frequent and more serious complications. ${ }^{12}$

\section{Limitations}

Our study is limited by its retrospective nature. A prospective, randomized controlled trial would be needed to minimize the introduction of bias into the study design. Nevertheless, the retrospective nature of this study allows us to collect and provide data from a large patient cohort. The study is further limited by the fact that different surgeons have different thresholds for operation and reoperation, which cannot be captured in this study and has been previously reported on. ${ }^{14}$ Most neurosurgeons base their decision to operate upon the initial hematoma volume and the patient's neurological status. They reoperate if the patient's neurological status worsens after the surgery or if the hematoma size or midline shift increases on CT.

\section{Conclusions}

The results of our study showed that use of warfarin or clopidogrel, mixed hypo- and isointensity in T1-weighted MRI, hematoma loculation, higher preoperative midline shift, greater hematoma/fluid thickness on the 1st post- operative day CT, decreased percent change in hematoma thickness following surgical evacuation, use of MAC, and absence of intraoperative irrigation were predictive of reoperation. Most importantly, our study found that $0 \%$, $50 \%$, and $100 \%$ changes in hematoma thickness following evacuation, were associated with $41 \%, 6 \%$, and $<1 \%$ reoperation rates, respectively.

\section{Acknowledgments}

We would like to thank Ms. Patricia Baum, MS, for her help with this study.

\section{References}

1. Abouzari M, Rashidi A, Rezaii J, Esfandiari K, Asadollahi $\mathrm{M}$, Aleali $\mathrm{H}$, et al: The role of postoperative patient posture in the recurrence of traumatic chronic subdural hematoma after burr-hole surgery. Neurosurgery 61:794-797, 2007

2. Almenawer SA, Farrokhyar F, Hong C, Alhazzani W, Manoranjan B, Yarascavitch B, et al: Chronic subdural hematoma management: a systematic review and meta-analysis of 34,829 patients. Ann Surg 259:449-457, 2014

3. Chon KH, Lee JM, Koh EJ, Choi HY: Independent predictors for recurrence of chronic subdural hematoma. Acta Neurochir (Wien) 154:1541-1548, 2012

4. Goto H, Ishikawa O, Nomura M, Tanaka K, Nomura S, Maeda K: Magnetic resonance imaging findings predict the recurrence of chronic subdural hematoma. Neurol Med Chir (Tokyo) 55:173-178, 2015

5. Ishibashi A, Yokokura Y, Adachi H: A comparative study of treatments for chronic subdural hematoma: burr hole drainage versus burr hole drainage with irrigation. Kurume Med J 58:35-39, 2011

6. Jack A, O'Kelly C, McDougall C, Findlay JM: Predicting recurrence after chronic subdural haematoma drainage. Can J Neurol Sci 42:34-39, 2015

7. Jang KM, Kwon JT, Hwang SN, Park YS, Nam TK: Comparison of the outcomes and recurrence with three surgical techniques for chronic subdural hematoma: single, double burr hole, and double burr hole drainage with irrigation. Korean J Neurotrauma 11:75-80, 2015

8. Jeong SI, Kim SO, Won YS, Kwon YJ, Choi CS: Clinical analysis of risk factors for recurrence in patients with chronic subdural hematoma undergoing burr hole trephination. Korean J Neurotrauma 10:15-21, 2014

9. Kim DH, Kim HS, Choi HJ, Han IH, Cho WH, Nam KH: Recurrence of the chronic subdural hematoma after burr-hole drainage with or without intraoperative saline irrigation. Korean J Neurotrauma 10:101-105, 2014

10. Kim J, Moon J, Kim T, Ahn S, Hwang G, Bang J, et al: Risk factor analysis for the recurrence of chronic subdural hematoma: a review of 368 consecutive surgical cases. Korean J Neurotrauma 11:63-69, 2015

11. Ko BS, Lee JK, Seo BR, Moon SJ, Kim JH, Kim SH: Clinical analysis of risk factors related to recurrent chronic subdural hematoma. J Korean Neurosurg Soc 43:11-15, 2008

12. Lega BC, Danish SF, Malhotra NR, Sonnad SS, Stein SC: Choosing the best operation for chronic subdural hematoma: a decision analysis. J Neurosurg 113:615-621, 2010

13. Leroy HA, Aboukaïs R, Reyns N, Bourgeois P, Labreuche J, Duhamel A, et al: Predictors of functional outcomes and recurrence of chronic subdural hematomas. J Clin Neurosci 22:1895-1900, 2015

14. Liu W, Bakker NA, Groen RJM: Chronic subdural hematoma: a systematic review and meta-analysis of surgical procedures. J Neurosurg 121:665-673, 2014

15. Mondorf Y, Abu-Owaimer M, Gaab MR, Oertel JMK: 
Chronic subdural hematoma-craniotomy versus burr hole trepanation. Br J Neurosurg 23:612-616, 2009

16. Ohba S, Kinoshita Y, Nakagawa T, Murakami H: The risk factors for recurrence of chronic subdural hematoma. Neurosurg Rev 36:145-150, 2013

17. Pang CH, Lee SE, Kim CH, Kim JE, Kang HS, Park CK, et al: Acute intracranial bleeding and recurrence after bur hole craniostomy for chronic subdural hematoma. J Neurosurg 123:65-74, 2015

18. Ro HW, Park SK, Jang DK, Yoon WS, Jang KS, Han YM: Preoperative predictive factors for surgical and functional outcomes in chronic subdural hematoma. Acta Neurochir (Wien) 158:135-139, 2016

19. Santarius T, Kirkpatrick PJ, Ganesan D, Chia HL, Jalloh I, Smielewski P, et al: Use of drains versus no drains after burr-hole evacuation of chronic subdural haematoma: a randomised controlled trial. Lancet 374:1067-1073, 2009

20. Schwarz F, Loos F, Dünisch P, Sakr Y, Safatli DA, Kalff R, et al: Risk factors for reoperation after initial burr hole trephination in chronic subdural hematomas. Clin Neurol Neurosurg 138:66-71, 2015

21. Singh AK, Suryanarayanan B, Choudhary A, Prasad A, Singh S, Gupta LN: A prospective randomized study of use of drain versus no drain after burr-hole evacuation of chronic subdural hematoma. Neurol India 62:169-174, 2014

22. Song DH, Kim YS, Chun HJ, Yi HJ, Bak KH, Ko Y, et al: The predicting factors for recurrence of chronic subdural hematoma treated with burr hole and drainage. Korean J Neurotrauma 10:41-48, 2014

23. Stanišić M, Hald J, Rasmussen IA, Pripp AH, Ivanović J, Kolstad F, et al: Volume and densities of chronic subdural haematoma obtained from CT imaging as predictors of postoperative recurrence: a prospective study of 107 operated patients. Acta Neurochir (Wien) 155:323-333, 2013

24. Stanisic M, Lund-Johansen M, Mahesparan R: Treatment of chronic subdural hematoma by burr-hole craniostomy in adults: influence of some factors on postoperative recurrence. Acta Neurochir (Wien) 147:1249-1257, 2005

25. Tahsim-Oglou Y, Beseoglu K, Hänggi D, Stummer W, Stei- ger HJ: Factors predicting recurrence of chronic subdural haematoma: the influence of intraoperative irrigation and low-molecular-weight heparin thromboprophylaxis. Acta Neurochir (Wien) 154:1063-1068, 2012

26. Unterhofer C, Freyschlag CF, Thomé C, Ortler M: Opening the internal hematoma membrane does not alter the recurrence rate of chronic subdural hematomas: a prospective randomized trial. World Neurosurg 92:31-36, 2016

27. Yu GJ, Han CZ, Zhang M, Zhuang HT, Jiang YG: Prolonged drainage reduces the recurrence of chronic subdural hematoma. Br J Neurosurg 23:606-611, 2009

\section{Disclosures}

The authors report no conflict of interest concerning the materials or methods used in this study or the findings specified in this paper.

\section{Author Contributions}

Conception and design: Thomas, Motiei-Langroudi. Acquisition of data: Motiei-Langroudi, Shi, Adeeb, Gupta. Analysis and interpretation of data: Thomas, Motiei-Langroudi, Stippler, Adeeb. Drafting the article: Motiei-Langroudi. Critically revising the article: Thomas, Motiei-Langroudi, Stippler, Griessenauer, Kasper, Arle, Alterman. Reviewed submitted version of manuscript: all authors. Statistical analysis: Motiei-Langroudi. Administrative/ technical/material support: Thomas, Motiei-Langroudi, Stippler, Papavassiliou, Kasper, Arle, Alterman, Ogilvy. Study supervision: Thomas, Stippler.

\section{Correspondence}

Ajith J. Thomas, Neurosurgical Service, Beth Israel Deaconess Medical Center, Harvard Medical School, 110 Francis St., Ste. 3B, Boston, MA 02215. email: athomas6@bidmc.harvard.edu. 